\title{
Viscosity Measurement of Silver Based Nano-inks
}

\author{
Peter Lukacs ${ }^{1 *}$, Alena Pietrikova ${ }^{1}$, Tibor Rovensky $^{1}$ \\ ${ }^{1}$ Department of Technologies in Electronics, Faculty of Electrical Engineering and Informatics, Technical University of Kosice, \\ Park Komenskeho 2, 04001 Kosice, Slovakia \\ *Corresponding author, e-mail: peter.lukacs@tuke.sk
}

Received: 15 October 2018, Accepted: 07 November 2018, Published online: 03 December 2018

\begin{abstract}
The paper deals with the analysis and viscosity measurement of five commonly available silver based nano-inks at different temperatures. The kind of solvent, dimension of nano-particles and temperature play a key role for the viscosity of nano-inks. For the controlling of the deposition process of nano-inks by inkjet printing technology, knowledge of the rheological properties of applied nano-inks are necessary. For this reason, this paper offers the theoretical description of applied test method as well as practical results from the viscosity measurements, which were done by rheometer MCR 502 Anton Paar. Furthermore, the paper offers the comparative study of the viscosity measurements of different kind of silver based nano-inks. The twin gap method was applied due to achieving of high accuracy of measurements.
\end{abstract}

Keywords

inkjet printing, nano-inks, viscosity, twin gap

\section{Introduction}

Nowadays, demands on the electronic circuits manufacture processes are more and more strict. There are a lot of possibilities of creation the silver paths, motives and electronic circuits which differ in dimensions of paths, electrical parameters and adhesion mechanism of deposited layers as well. InkJet Printing is a digital printing technology in which the drops of nano-ink are jetted from the nozzle directly onto specific places on flexible or rigid substrate. The development of materials in nano-size dimensions opens the new doors in the field of technologies in electronics which makes the inkjet printing technology possible to use for manufacturing processes [1-3].

The deposition process of nano-inks and generation of drops predominantly depend on the rheological properties of used nano-inks. Solvent, percentage of the solid material, shape and dimension of nano-inks, surface tension, and density but also the parameters of inkjet printer, such as the nozzle diameter or the controlling signal and pressure have the significant impact on the drop spreading on the substrate. Immediately after the impact of the silver based nano-ink drops onto the surface, the surface tension activates the spreading which affects the final shape of the deposited pattern. In the case of such small volume of nano-fluid the inadmissible changes can cause the irreversible influences on the quality of the deposition process. It is generally known, that the shear viscosity depends on the physical and chemical consistence of the liquid, temperature, pressure, time and shear rate. Each one from these parameters can critically changes the deposition process [4-7].

The jettability of the nano-ink mainly depends on rheological properties such as viscosity, density and surface tension. On the other hand these properties influence the size and shape of the deposited droplets, the behavior of drops and indicate the wetting of substrate. It is necessary to have a viscosity of the nano-ink in the range of 1-25 $\mathrm{mPa} \cdot \mathrm{s}$ and the surface tension between 25 and $50 \mathrm{mNm}^{-1}$. The effect of the nano-inks' properties and other parameters such as the nozzle diameter can be quickly assessed using the dimensionless Reynolds $\left(\mathrm{R}_{\mathrm{e}}\right)$, Weber $\left(\mathrm{W}_{\mathrm{e}}\right)$ and Ohnesorge $\left(\mathrm{O}_{\mathrm{h}}\right)$ numbers [5].

The Reynolds number is the ratio of the inertial forces to the viscous forces and is defined by:

$R_{e}=\rho V L / \eta$.

The Weber number $\mathrm{W}_{\mathrm{e}}$ is the ratio of the inertial forces to the surface tension forces and is calculated as:

$W_{e}=\rho V^{2} L / \sigma$. 
The Ohnesorge $\mathrm{O}_{h}$ number describes the droplet formation and is the ratio of the viscous forces to the surface tension and inertial forces such that:

$O_{h}=\sqrt{W_{e}} / R_{e}=\eta / \sqrt{\rho L \sigma}$.

where,

$\rho$ is the density,

$\eta$ is the viscosity,

$\sigma$ is the surface tension,

$L$ is the nozzle diameter,

$V$ is the droplet velocity.

For measurement of the viscosity of nanofluids, the rotational rheometer, the piston-type rheometer and the capillary viscometer are the most popular tools. Rotational rheometers use the method that the torque required to turn an object in a fluid is a function of the viscosity. The relative rotation determines the shear stress under different rates [8].

As it was mentioned earlier, the particle size has the influence on the viscosity of nanofluids. The Krieger model can be used to estimate the relative viscosity between a nanofluid (nf) and its base fluid $(f)$ [8],

$\eta_{n f} / \eta_{f}=\left(1-\left(\Phi_{a} / \Phi_{m}\right)\right)^{-2.5 \Phi_{m}}$

where,

2.5 is the intrinsic viscosity of spherical particles,

$\Phi_{a}$ is the volume fraction of aggregates,

$\Phi_{m}$ is the volume fraction of densely packed spheres.

The volume fraction of aggregates is expressed as

$\Phi_{a}=\Phi\left(d_{a} / d\right)^{3-d_{f}}$

where,

$d_{a}$ is the diameter of aggregates,

$d$ is the nominal diameter of particle,

$d_{f}$ is the fractal dimension of the aggregates,

$\Phi$ is the volume fraction of the well-dispersed individual particles.

One of the biggest drawback in the case of inkjet printing technology is the complicated setting of the controlling signal values and pressure. Development of the automatic system or algorithm for setting and regulation of the controlling signal can radically simplifying the whole deposition process. Results presented in this paper can be helpful for finding the correlation between the nano-inks parameters (e.g. size of nanoparticles or percentage of silver), temperature and viscosity. Viscosity of applied nano-ink influences the ink spreading on the substrates surfaces resulting in a homogeneity creation and last but not least the final diameter of printed dot is depended on the viscosity of nano-ink as well. The preparation of the digital pattern which will be printed has to be subordinated to ink spreading $[3,5,9]$.

For the reason of optimizing the deposition process of drops, the viscosity of silver based nano-inks has been measured by twin gap test method at three different temperatures. Viscosity measurements have been carried out for contribution to finding the correlation between the viscosities of nano-inks and the controlling signal which controls the piezo element in the print head and generates the drop. The results are presented next in the paper.

\section{Experimental}

When very low viscosity liquids have to be measured, it is often desirable to use a double concentric cylinder arrangement, often referred as a twin gap method, shown in the Fig. 1. The principle of the twin gap method lays on the measuring of the shear rate and shear stress by rotation of the upper cylinder. The twin gap method requires just a small amount of the investigated solution or liquid, up to 1 $\mathrm{ml}$. The described test method is characterized by high precise measurements of low viscosity liquids. For this reason the twin gap method has been selected for our measurements of the investigated silver based nano-inks [10-17].

For the viscosity measurements, the rheometer MCR 502 Anton Paar has been selected while gap dimension has been $0.328 \mathrm{~mm}$ and the radius of upper plate $7.93 \mathrm{~mm}$. For the viscosity measurements, $0.3 \mathrm{ml}$ of silver based nano-inks has been applied for every investigated nanoink. The shear rate has been changed from 20 to $200 \mathrm{~s}^{-1}$ with the step of $10 \mathrm{~s}^{-1}$.

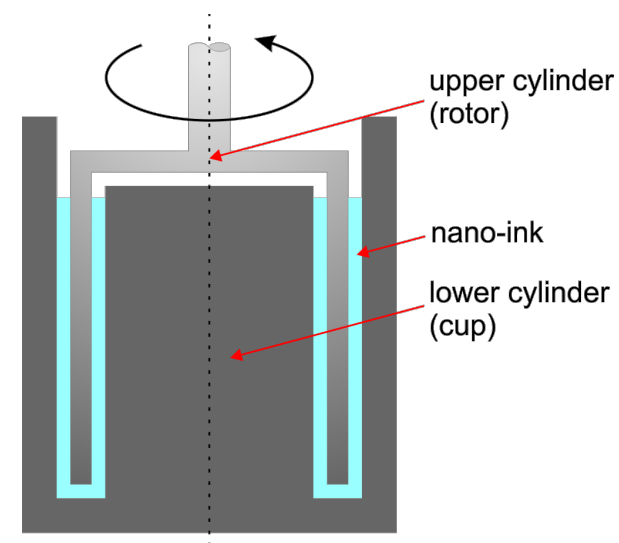

Fig. 1 Principle of twin gap viscosity measurement 
The selected specifications of investigated silver based nano-inks from datasheets are listed in the Table 1. In the case of the nano-ink Sigma Aldrich 736503, particle size and viscosity have not be stated in the datasheet.

For the reason of possibility of heating the printing nozzle during the deposition process of silver based nanoinks, the viscosity has been measured at three temperatures, 20, 30 and $40{ }^{\circ} \mathrm{C}$. These temperatures presents the most applied deposition conditions during the drops generation. Heating up the nozzle during the deposition process is an easy way how to control or change the viscosity of nano-inks without the necessity of modifying or changing the chemical composition of nano-inks. The behavior of drops after the impact on the substrate is mainly dependent on the viscosity on used nano-inks. For this reason the knowledge of the viscosity of used nano-inks is necessary during the parameters setting of inkjet printer.

\section{Results}

Dependences of the viscosity on shear rate at temperatures 20, 30 and $40^{\circ} \mathrm{C}$ are shown in the Fig. 2 to Fig. 6 for investigated nano-inks listed in the Table 1 respectively.

In the Fig. 2, the dependence of the viscosity on shear rate at three different temperatures for nano-ink JP-6n is shown. As it can be seen, the viscosity at $20^{\circ} \mathrm{C}$ is about $7 \mathrm{mPa} \cdot \mathrm{s}$, at $30{ }^{\circ} \mathrm{C}$ is about $5.3 \mathrm{mPa} \cdot \mathrm{s}$ and at $40{ }^{\circ} \mathrm{C}$ is about $4.2 \mathrm{mPa} \cdot \mathrm{s}$.

In the Fig. 3, the dependence of the viscosity on shear rate at three different temperatures for nano-ink JP-60n is shown. As it can be seen, the viscosity at $20^{\circ} \mathrm{C}$ is about $6 \mathrm{mPa} \cdot \mathrm{s}$, at $30{ }^{\circ} \mathrm{C}$ is about $4.4 \mathrm{mPa} \cdot \mathrm{s}$ and at $40{ }^{\circ} \mathrm{C}$ is about $3 \mathrm{mPa} \cdot \mathrm{s}$.

In the Fig. 4, the dependence of the viscosity on shear rate at three different temperatures for nano-ink UTDAg40IJ is shown. As it can be seen, the viscosity at $20{ }^{\circ} \mathrm{C}$ is about $14.5 \mathrm{mPa} \cdot \mathrm{s}$, at $30{ }^{\circ} \mathrm{C}$ is about $11.2 \mathrm{mPa} \cdot \mathrm{s}$ and at $40{ }^{\circ} \mathrm{C}$ is about $8.65 \mathrm{mPa} \cdot \mathrm{s}$.

Table 1 Selected specifications of investigated nano-inks [18-22]

\begin{tabular}{lccc}
\hline Nano-ink & $\begin{array}{c}\text { Percentage } \\
\text { of silver [\%] }\end{array}$ & $\begin{array}{c}\text { Particle } \\
\text { size [nm] }\end{array}$ & $\begin{array}{c}\text { Viscosity } \\
{[\mathbf{m P a} \cdot \mathbf{s}]}\end{array}$ \\
\hline $\begin{array}{l}\text { Amepox Microelectronics, } \\
\text { Ltd. AX JP-6n }\end{array}$ & $40-60$ & $3-7$ & $7.5-10.5$ \\
$\begin{array}{l}\text { Amepox Microelectronics, } \\
\text { Ltd. AX JP-60n }\end{array}$ & 20 & $50-60$ & $5-6.5$ \\
$\begin{array}{l}\text { UTDots, Inc. UTDAg40IJ } \\
\text { Sigma-Aldrich 736503 }\end{array}$ & $25-60$ & 10 & $1-30$ \\
$\begin{array}{l}\text { Novacentrix Metalon } \\
\text { JS-B40G }\end{array}$ & $50-60$ & not stated & not stated \\
\hline
\end{tabular}

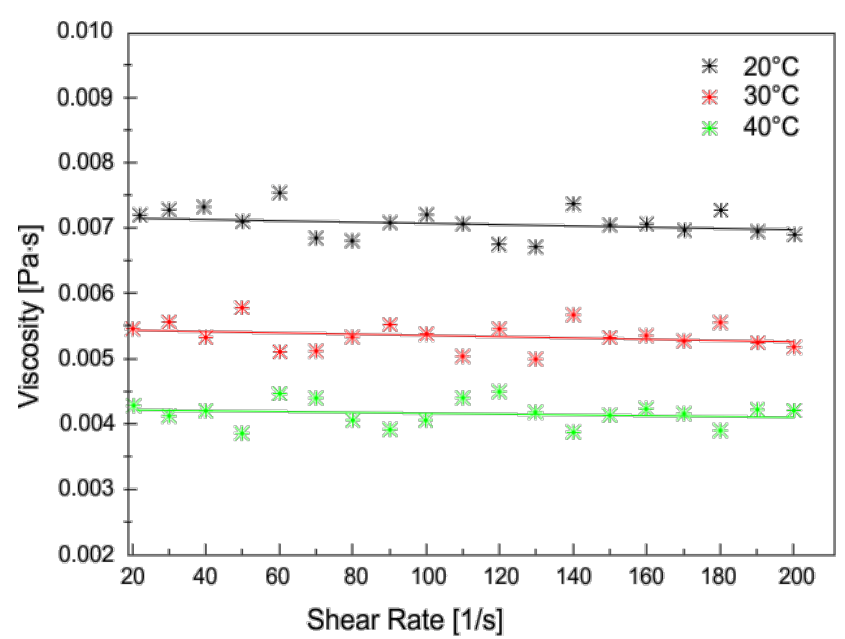

Fig. 2 Viscosity of nano-ink Amepox Microelectronics, Ltd. - AX JP-6n

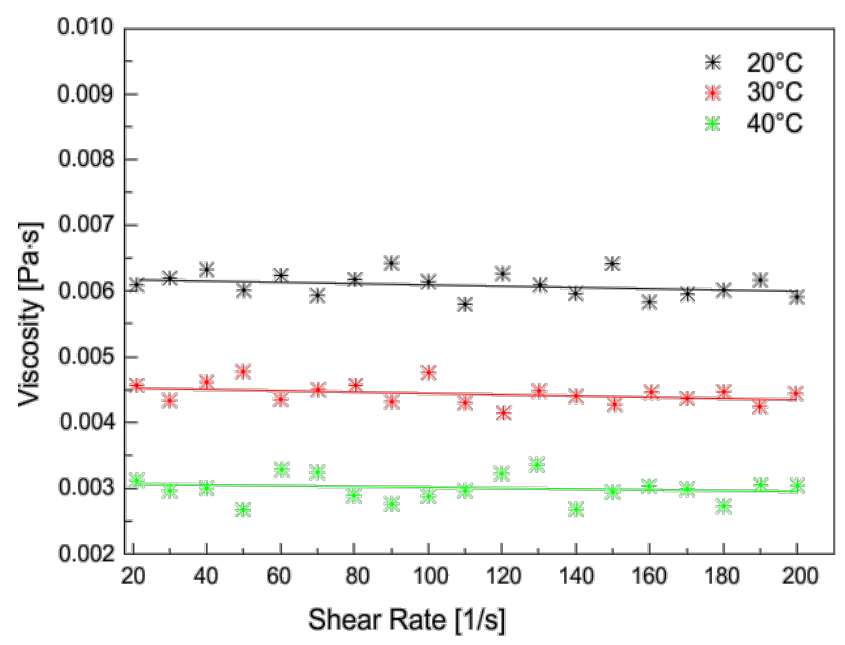

Fig. 3 Viscosity of nano-ink Amepox Microelectronics, Ltd. - AX JP-60n

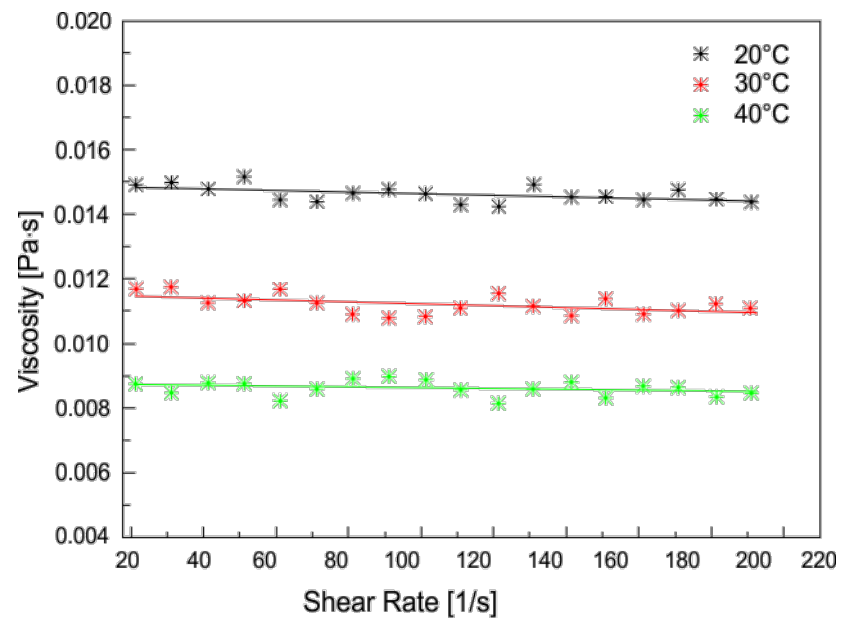

Fig. 4 Viscosity of nano-ink UTDots, Inc. - UTDAg40IJ

In the Fig. 5, the dependence of the viscosity on shear rate at three different temperatures for nano-ink 736503 is shown. As it can be seen, the viscosity at $20{ }^{\circ} \mathrm{C}$ is about 


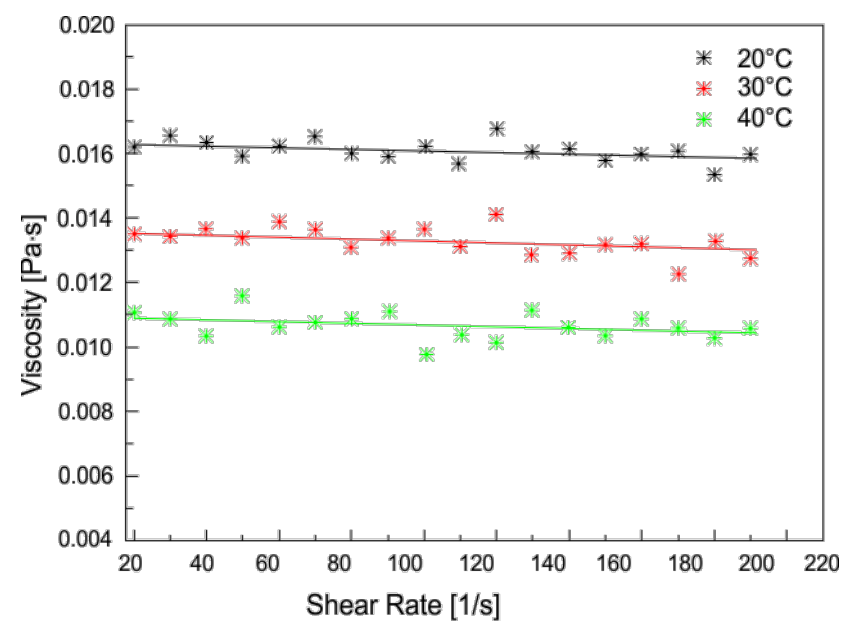

Fig. 5 Viscosity of nano-ink Sigma-Aldrich - 736503

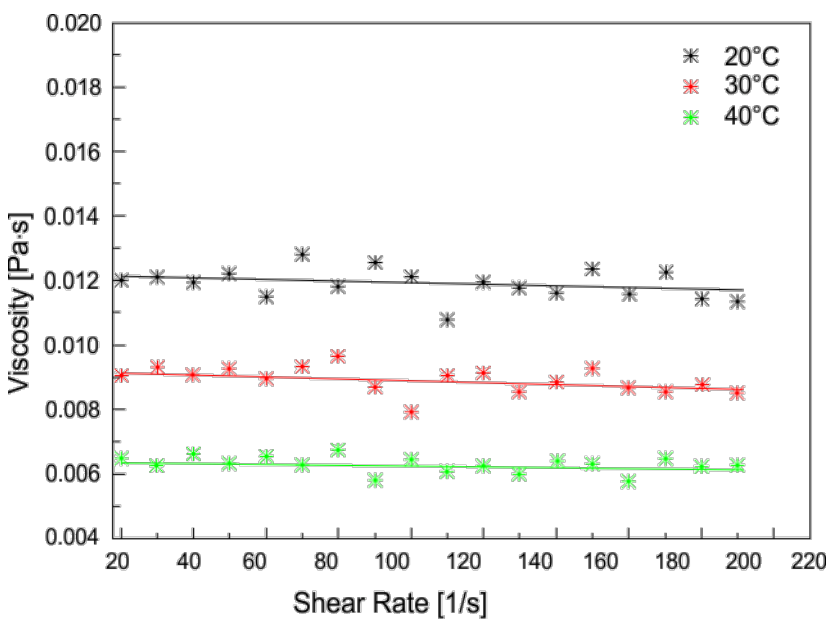

Fig. 6 Viscosity of nano-ink Novacentrix - Metalon JS-B40G

$16 \mathrm{mPa} \cdot \mathrm{s}$, at $30{ }^{\circ} \mathrm{C}$ is about $13.3 \mathrm{mPa} \cdot \mathrm{s}$ and at $40{ }^{\circ} \mathrm{C}$ is about $10.7 \mathrm{mPa} \cdot \mathrm{s}$.

In the Fig. 6, the dependence of the viscosity on shear rate at three different temperatures for nano-ink JS-B40G is shown. As it can be seen, the viscosity at $20{ }^{\circ} \mathrm{C}$ is about $11.9 \mathrm{mPa} \cdot \mathrm{s}$, at $30{ }^{\circ} \mathrm{C}$ is about $8.9 \mathrm{mPa} \cdot \mathrm{s}$ and at $40{ }^{\circ} \mathrm{C}$ is about $6.2 \mathrm{mPa} \cdot \mathrm{s}$.

The lowest viscosity has been measured in the case of nano-ink AX JP-60n (Fig. 3). The viscosity of this nanoink is less than $3 \mathrm{mPa} \cdot \mathrm{s}$ at the temperature $40{ }^{\circ} \mathrm{C}$ and shear rate $200 \mathrm{~s}^{-1}$. On the other side, the highest viscosity has been measured for the nano-ink Sigmal-Aldrich 736503 (Fig. 5), more than $16 \mathrm{mPa} \cdot \mathrm{s}$ at the temperature $20^{\circ} \mathrm{C}$ and shear rate $20 \mathrm{~s}^{-1}$.

In the Table 2, values from the viscosity measurements at shear rate 20 and $200 \mathrm{~s}^{-1}$ are listed for every investigated silver based nano-inks. As it is clear from the presented results, the viscosity of analyzed silver based nano-inks is
Table 2 Measured viscosity of analyzed nano-inks at the shear-rate 20 and $200 \mathrm{~s}^{-1}$

\begin{tabular}{|c|c|c|c|}
\hline Nano-ink & $\begin{array}{c}\text { Temperature } \\
{\left[{ }^{\circ} \mathrm{C}\right]}\end{array}$ & $\begin{array}{l}\text { Viscosity } \\
\text { at } 20 \mathrm{~s}^{-1} \\
{[\mathrm{mPa} \cdot \mathrm{s}]}\end{array}$ & $\begin{array}{l}\text { Viscosity } \\
\text { at } 200 \mathrm{~s}^{-1} \\
{[\mathrm{mPa} \cdot \mathrm{s}]}\end{array}$ \\
\hline \multirow{3}{*}{$\begin{array}{l}\text { Amepox } \\
\text { Microelectronics, Ltd. } \\
\text { AX JP-6n }\end{array}$} & 20 & 7.22 & 6.98 \\
\hline & 30 & 5.48 & 5.26 \\
\hline & 40 & 4.25 & 4.12 \\
\hline \multirow{3}{*}{$\begin{array}{l}\text { Amepox } \\
\text { Microelectronics, Ltd. } \\
\text { AX JP-60n }\end{array}$} & 20 & 6.15 & 6 \\
\hline & 30 & 4.54 & 4.35 \\
\hline & 40 & 3.16 & 2.97 \\
\hline \multirow{3}{*}{$\begin{array}{l}\text { UTDots, Inc. } \\
\text { UTDAg40IJ }\end{array}$} & 20 & 14.83 & 14.32 \\
\hline & 30 & 11.5 & 10.95 \\
\hline & 40 & 8.8 & 8.5 \\
\hline \multirow{3}{*}{$\begin{array}{l}\text { Sigma-Aldrich } \\
736503\end{array}$} & 20 & 16.2 & 15.9 \\
\hline & 30 & 13.51 & 13.04 \\
\hline & 40 & 10.95 & 10.44 \\
\hline \multirow{3}{*}{$\begin{array}{l}\text { Novacentrix Metalon } \\
\text { JS-B40G }\end{array}$} & 20 & 12.19 & 11.76 \\
\hline & 30 & 9.16 & 8.78 \\
\hline & 40 & 6.3 & 6.11 \\
\hline
\end{tabular}

dependent on the shear rate. By increasing the shear rate the viscosity decreases. The highest viscosity decrease has been observed in the case of the nano-ink UTDAg40IJ.

Another notable result is a more pronounced viscosity decrease when the temperature has been increased from $20{ }^{\circ} \mathrm{C}$ to $30^{\circ} \mathrm{C}$ in comparison with the temperature change from $30^{\circ} \mathrm{C}$ to $40^{\circ} \mathrm{C}$.

After the detailed analysis of investigated silver based nano-inks' consistence, the dependence of the viscosity on the Ag content (\%wt) has been also proved. The lowest viscosity has been measured in the case of the nano-ink Amepox JP-60n which has the lowest silver concentration only $20 \%$. In the case of other nano-inks the silver concentration has been higher what was reflected in the higher viscosity. In the case of nano-inks UTDAg40IJ and SigmaAldrich 736503 the concentration of the silver is up to $60 \%$. Hence the viscosity of these nano-inks has been the highest.

\section{Discussion}

The aim of this paper is based on the necessity of knowledge the viscosity values of applied nano-inks. Rheological properties of silver based nano-inks has the great impact on the nano-inks' behavior during and immediately after the deposition process. Not only the drop generation but also the behavior of the drops on the polymeric substrate surface is influenced by viscosity and surface tension of nano-inks. When precise structures are printed by inkjet 
printing technology, the shape and volume of drops have the negligible impact on the spreading and homogeneity of created structures or lines. For this reason, the adjustment of the signal which controls the piezo-element in the nozzle is easier when the technologist knows the viscosity value of applied nano-ink. Different shapes of nano-particles, used solvent and other chemical agents incite the necessity of finding the optimal deposition parameters for every nanoink. The results described in this paper prove the strong dependence of temperature on the nano-inks viscosity.

The prediction of the drops' parameters, as well as the ink spreading and final dot diameter is very difficult for the reason of lot of parameters of the nano-inks, substrates and technological aspects. In addition the nanoink parameters given by manufacturers on the data sheets are often inaccurate or are given in the very wide range. During the printing, the substrate has to be heated up for the reason of optimizing the ink spreading. The print head is warming up from the substrate during the printing. For this reason, the viscosity changes are appreciably and there is the necessity of modifying the controlling signal during the deposition process.

The percentage of silver of investigated nano-inks is up to $60 \%$ in the case of JP-6n, UTAg40IJ and 736503, which has the certain effect on the inks viscosity. The lowest percentage of silver is stated in the case of the nano-ink JP-60n $20 \%$. Analyzed silver based nano-inks have the stated viscosities in datasheets in the range from 3 up to $80 \mathrm{mPa} \cdot \mathrm{s}$ with the exceptation of the nano-ink 736503 where the values of viscosity and particle size have not been stated. Definitely the lowest particle size has been stated for the nano-ink JP-6n, only 3-7 nm. For other investigated nanoinks the particles sizes have been higher, up to $80 \mathrm{~nm}$.

\section{References}

[1] Tomaszewski, G., Potencki, J., Wałach, T. "Packing density of inkjet printed paths", Circuit World, 44(1), pp. 21-28, 2018. https://doi.org/10.1108/CW-10-2017-0055

[2] Pietrikova, A., Lukacs, P., Jakubeczyova, D., Ballokova, B., Potencki, J., Tomaszewski, G., Pekarek, J., Prikrylova, K., Fides, M. "Surface analysis of polymeric substrates used for inkjet printing technology", Circuit World, 42(1), pp. 9-16, 2016. https://doi.org/10.1108/CW-10-2015-0047

[3] Tomaszewski, G., Potencki, J., Wałach, T., Pilecki, M. "Investigation of ink spreading on various substrates in inkjet technology", Elektronika - Konstrukcje, Technologie, Zastosowania, 1(3), pp. 27-29, 2015. https://doi.org/10.15199/13.2015.3.6
The behavior of investigated silver based nano-inks can be considered as Newtonian liquid in the range of the shear rate from 20 to $200 \mathrm{~s}^{-1}$. In the case of lower shear rate, the dependence of viscosity on the shear rate can be markedly changed.

\section{Conclusion}

Viscosity measurements of five generally available silver based nano-inks at different temperatures have been presented. The twin gap viscosity test method has been selected for measurements. The paper offers the comparative study of investigated silver based nano-inks' viscosities in regard to temperature, particle size and silver concentration.

The lowest viscosity has been measured in the case of the nano-ink Amepox JP-60n, $6.15 \mathrm{mPa} \cdot \mathrm{s}$, while the highest viscosity has been measured for the nano-ink SigmaAldrich 736503, $16.2 \mathrm{mPa} \cdot \mathrm{s}$. This paper offers the accurate values of viscosities at three different temperatures and different shear rates, from 20 to $200 \mathrm{~s}^{-1}$. Presented results can be applied into the optimization process of the deposition of silver based nano-inks. The correlation between the silver concentration, particle size, temperature and viscosity has been presented.

\section{Acknowledgement}

This work was supported by the Slovak Research and Development Agency under the contract No. APVV-140085: Development of New Generation Joints of Power Electronics Using Nonstandard Sn-Based Alloys.

This paper was supported by VEGA project 1/0141/18.

This paper was supported by KEGA project 021TUKE-4/2017.

[4] Murshed, S. M. S., Leong, K. C., Yang, C. "Investigations of thermal conductivity and viscosity of nanofluids", International Journal of Thermal Sciences, 47(5), pp. 560-568, 2008. https://doi.org/10.1016/j.ijthermalsci.2007.05.004

[5] Cummins, G., Desmulliez, M. P. Y. "Inkjet printing of conductive materials: a review", Circuit World, 38(4), pp. 193-213, 2012. https://doi.org/10.1108/03056121211280413

[6] Lukács, P., Pietriková, A., Potencki, J., Tomaszewski, G. "The Deposition Process Optimization by Controlling of the Piezo Elements in the Print Head", Acta Electrotechnica et Informatica, 16(3), pp. 14-19, 2016. https://doi.org/10.15546/aeei-2016-0018 
[7] Martinek, P., Krammer, O. "Optimising pin-in-paste technology using gradient boosted decision trees", Soldering \& Surface Mount Technology, 30(3), pp. 164-170, 2018. https://doi.org/10.1108/SSMT-09-2017-0024

[8] Fei, D. "Thermal Property Measurement of Al2O3-Water Nanofluids", In: Hashim. A. (ed.) Smart Nanoparticles Technology, InTech, Croatia, 2012. https://doi.org/10.5772/33830

[9] Kováč, O., Gladišová, I. "Multifocal Images Fusion", Acta Electrotechnica et Informatica, 17(3), pp. 22-26, 2017. https://doi.org/10.15546/aeei-2017-0022

[10] Acrivos, A., Fan, X., Mauri, R. "On the measurement of the relative viscosity of suspensions", Journal of Rheology, 38(5), pp. 1285-1296, 1994.

https://doi.org/10.1122/1.550544

[11] Marvin, R. S. "The Accuracy of Measurements of Viscosity of Liquids", Journal of Research of the National Bureau of Standards - A. Physics and Chemistry, 75A(6), pp. 535-540, 1971.

[12] Hiemenz P. C., Rajagopalan, R. "Principles of Colloid and Surface Chemistry", 3rd ed., Marcel Dekker, Inc., New York, 1997.

[13] Andrade, R. M., Pereira, A. S., Soares, E. J. "Drag Reduction in Synthetic Seawater by Flexible and Rigid Polymer Addition Into a Rotating Cylindrical Double Gap Device", Journal of Fluids Engineering, 138(2), pp. 021101-021101-10, 2015.

https://doi.org/10.1115/1.4031229
[14] Pietrikova, A., Kravcik, M. "Investigation of rheology behavior of solder paste", In: 2012 35th International Spring Seminar on Electronics Technology (ISSE), Bad Aussee, Austria, 2012, pp. 138-143.

https://doi.org/10.1109/isse.2012.6273124

[15] Tóthová, J., Kováč, Kopčanský, P., Rajňák, M., Paulovičová, K., Timko, M., Józefczak, A. "Viscosity Dependence of a Magnetic Fluid Nanoparticles Concentration", Acta Physica Polonica A, 126(1), pp. 278-279, 2014.

https://doi.org/10.12693/aphyspola.126.278

[16] Mezger, T. G. "The rheology handbook for users of rotational and oscillatory rheometers", Hannover, Vincentz Network, 2006.

[17] Pipe, C. J., McKinley, G. H. "Microfluidic rheometry", Mechanics Research Communications, 36(1), pp. 110-120, 2009. https://doi.org/10.1016/j.mechrescom.2008.08.009

[18] Amepox Microelectronics, Ltd. "Nano Ink JP-6n".

[19] Amepox Microelectronics, Ltd. "Nano Ink JP-60n".

[20] UTDots, Inc. "UTDAg40IJ".

[21] Sigma-Aldrich "736503".

[22] Novacentrix Metalon "JS-B40G", 2015. 